\title{
The Influence of Online Brand Community Experience on Brand Loyalty
}

$$
\text { Jia-Li TANG }{ }^{1, a,{ }^{*}} \text { and Duan-Wu YAN }{ }^{2, b}
$$

${ }^{1,2}$ School of Economics and Management, Nanjing University of Science and Technology, Nanjing,
Jiangsu, China

ajiali_tang@163.com, ${ }^{\text {b }}$ yanwu123@sina.com

Keywords: online brand community; community experience; community commitment; brand loyalty; community participation

\begin{abstract}
This paper discusses the influence of online brand community on brand loyalty from the perspective of community experience with five dimensions: information experience, entertainment experience, interactive experience, thinking experience and service experience. It is found that the impact has two paths: one is that online brand community experience has a direct positive effect on brand loyalty, and the other is that community commitment plays a partial mediating effect between both. Specifically, information experience, thinking experience and service experience positively influence brand loyalty, while entertainment experience and interactive experience have no significant influence on brand loyalty. What's more, there was no moderating effect of community participation on the relationship among experience, community commitment and brand loyalty.
\end{abstract}

\section{Introduction}

Brand community research originates in 2001, when Muniz and O’Guinn ${ }^{[1]}$ defined brand community as "specialized, non-geographically bound community, based on a structured set of social relations among admirers of a brand" with three key characteristics: consciousness of kind, shared rituals and traditions and moral responsibility. With the development of Internet technology, brand community gradually shifts from the physical community to the virtual community. Now, an increasing number of companies regard the online brand community as an important platform to strengthen the link between consumers and brands, such as Huawei, Apple, Starbucks and the like. How to effectively manage the online brand community to make it bring brand performance and create economic value become an important issue of enterprise.

Through reviewing the research history of online brand community, we find that the impact of online brand community on brand loyalty has always been a hot topic. Related researches mainly focus on community relations (such as community involvement, community identity, community trust, etc.), perceived value, social networks and customer experience. There are relatively few researchers to study the relationship between brand community and brand loyalty from the perspective of experience. Schouten ${ }^{[2]}$ found that transcendent customer experiences (TCE) in the context of a marketer-facilitated consumption activity can strengthen a person's ties to a brand community, delivering a particularly strong form of brand loyalty. Xue and Wang ${ }^{[3]}$ verified that the TCE has a significant positive impact on brand loyalty, while brand attachment and brand addiction play a positive intermediary between both. TCE, as the highest level of consumer experience, indeed can give consumers the ultimate pleasure and have a positive impact on brand loyalty. However, it did not systematically reveal the influence of different experience dimensions on brand loyalty. Thus, learning from Holbrook's "four Es" ${ }^{\text {"[4] }}$ and flow experience theory ${ }^{[5]}$, Ren ${ }^{[6]}$ divided brand community experience into five dimensions: experience, entertainment, exhibitionism, evangelizing and flow experience and found that the five experiences play a positive role in brand community integration. However, it can not cover the whole contents of the community experience. Hence, we will further discuss the division of community experience and take Huawei online community as the research object to explore the influence of experience on brand loyalty. 


\section{Theoretical Background and Research Hypothesis}

\section{Online Brand Community Experience}

The coming of experience economy and the rising of online social media offer the enterprise an opportunity to connect customers with brand by online community. Scholars have also begun to focus on the online brand community experience. Cova ${ }^{[7]}$ found that when the experience is consistent with consumers' expectations, they tend to face brand marketing activities with a positive attitude. It is obvious that community experience has some effect on consumer thinking and behavior. Nambisan and $\mathrm{Watt}^{[8]}$ defined an online community experience as "the overall experience a customer derives from his/her interactions in an online community" with four dimensions: pragmatic dimension, hedonic dimension, sociability dimension, and usability dimension. Sha ${ }^{[9]}$ pointed out that online brand community consist of interaction experience, entertainment experience and information experience. Xue ${ }^{[10]}$ believed that brand community experience includes entertainment experience, missionary experience, immersive experience, aesthetic experience and transcendent experience. Although the division of community experience is different, information, interaction and entertainment seem to be three common dimensions. When the community develops to a certain extent, the multi-directional interaction among members can inspire them to think and create some inconceivable ideas. It will be contribute positively to the production and reproduction of various products and values. If online brand community can provide services for specific target groups, consumer brand loyalty will be strengthened. Therefore, we will study online community experience from five dimensions: information, entertainment, interaction, thinking and service.

\section{Community Experience and Brand Loyalty}

There have been many scholars conducting empirical analysis about the relationship between experience and brand loyalty, such as Schouten ${ }^{[2]}, \mathrm{Xue}^{[3]}$ and Ren ${ }^{[6]}$. However, they did not explore the direct impact of experience on brand loyalty. So this paper will explore the direct impact of community experience on brand loyalty and propose a hypothesis:

H1: Online brand community experience will positively affect brand loyalty.

The community experience is divided into five dimensions: information, entertainment, interaction, thinking and service. Information experience refers to the experience that community members acquire or share information. If the community can provide consumers with valuable information, consumers' perceived uncertainty will be reduced, which enhance their willingness to buy products $^{[11]}$. Entertainment experience is a sense of relaxation and happiness that members get in the community. There are some studies showing that companies who often produce entertaining content can get consumer attention and favor more easily ${ }^{[12]}$. Interactive experience means the experience of interaction and communication among members. Through interactive communication, you can establish a strong link with like-minded members to form a common community emotions, affecting their relationship with the brand. Thinking experience refers to the experience that certain activities or topic discussions can attract members' attention and inspire them to think deeply to acquire specific knowledge or solve some problems. Sometimes, the creative ideas of members may promote the brand continuously self-improvement, so that members can appreciate the pleasure and satisfaction of growing with the brand together. Service experience is the experience that a community member can get in the community to meet his or her specific needs. Good service can improve the members' satisfaction of the community, and thus affect their brand loyalty. Therefore, the following hypotheses are further proposed:

H1(a): Information experience will positively affect brand loyalty.

H1(b): Entertainment experience will positively affect brand loyalty.

H1(c): Interactive experience will positively affect brand loyalty.

H1(d): Thinking experience will positively affect brand loyalty.

H1(e): Service experience will positively affect brand loyalty.

\section{The Mediating Role of Community Commitment}


The discussion of brand community commitment can be traced back to organizational commitment. Organizational commitment is the individual's psychological attachment to the organization ${ }^{[13]}$. We extend this concept to the brand community. Community members with higher community commitment are more likely to have a sense of identity and a sense of belonging to the community, and choose to stay in the community, continuing to perceive the brand products. It may influence brand loyalty. Therefore, this paper will introduce brand community commitment as an intermediary variable into the research model.

Generally, the initial motivation of consumers to participate in brand communities is information motivation ${ }^{[14]}$. However, with the increase of community experience and the establishment of trust, the heterogeneity between community and new members is weakened and the homogeneity is increased, and the weak relationship gradually transforms into strong relationship ${ }^{[10]}$. Members can make friends with some like-minded people and extend their social networks. It can bring them a sense of satisfaction and belonging different from acquaintance social activities, which may make members produce psychological attachment to the community. Therefore, the following hypothsis is proposed:

H2: Online brand community experience will positively affect community commitment.

Brand community and brand are two concepts, but in fact, there is a certain relationship between both. Zhou ${ }^{[16]}$ pointed out that the prerequisite of community commitment transformed into brand promise is that there is a similarity between the community and the brand, and the greater the similarity, the greater the probability that the brand community will be transformed into the brand promise will be. Various community actions, including posting, topic discussion, the interaction between members, are mostly taken around the brand. Members with higher community commitment tend to be active participators and are very happy to help other members, showing a behavioral bias that is consistent with community norms ${ }^{[1]}$. That is to say, they will be more willing to recommend the brand to others. Therefore, the following hypothsis is proposed:

H3: Community commitment will positively affect brand loyalty.

\section{Moderating Effect of the Degree of Community Participation}

Community participation refers to the process of consulting, collecting and sharing brand-related information, communicating with other members and participating in community- defined activities by discussing, browsing, posting, replying, forwarding, and other ways. In fact, the degree of members' community participation is different. Some rarely take the initiative to participate in activities or topic discussion, they just browse the post to find the information they need, while some actively participate in various activities in the community and communicate more actively with other members. Fan ${ }^{[16]}$ argued that the degree of network interaction participation has a positive effect on members network interaction utility, and also affect the purchase intention and behavior. Thus, the following hypotheses are proposed:

H4: The degree of community participation is positively regulating the relationship between community experience and community commitment.

H5: The degree of community participation is positively regulating the relationship between community experience and brand loyalty.

H6: The degree of community participation is positively regulating the relationship between community commitment and brand loyalty.

\section{Empirical Research Design and Results}

\section{Scale Design}

In order to ensure the reliability and validity of the measurement tool, we refered to the relevant researches' scale items. According to the object of this study, we have made specific changes and adjustments. We use Likert 7 scale to measure the feelings of the respondents. The online community experience scale is based on the work of Sha ${ }^{[9]}$, Schmitt ${ }^{[17]}$ and Fan ${ }^{[11]}$. The community 
commitment scale reference to Allen et al's organizational commitment scale ${ }^{[18]}$. The brand loyalty scale is based on the work of bao ${ }^{[19]}$. The degree of community participation scale is based on the research of Madup ${ }^{[20]}$.

\section{Questionnaire Design and Collection}

The main body of the questionnaire includes two parts. The first part is the demographic problems, including the gender, age, education, occupation and admission time. The second part is divided into four modules: online brand community experience, brand community commitment, brand loyalty and community participation, a total of 32 items.

In this study, we take the Huawei brand as an example to study the impact of its online brand community experience on brand loyalty. Therefore, we use the Wenjuanxing to create an online questionnaire. The questionnaire was released into several online platforms, including Pollen Club, Mobile China Huawei Forum, Huawei Tianya Forum, Huawei Baidu Post Bar. Before the official questionnaire release, we conducted a small range of pre-test, and improve the questionnaire according to feedback. Then we officially released the questionnaire in the relevant platforms, lasting two weeks. We received a total of 257 questionnaires. Finally, we received 197 valid questionnaires, and questionnaires returned pass rate is $76.7 \%$.

In this survey, Huawei community male members accounted for the majority, up to $70.56 \%$. The reason may be that during the survey, Huawei is taking the business style, more favored by male consumers. Members aged from 18 to 30 accounted for $79.19 \%$. It can be seen that online brand community such new things are more popular with young people. Relatively speaking, the middle-aged and the old pay lesser attention to the online brand community. What's more, the vast majority of members are the students. The membership of more than 6 months are the majority, and the membership of more than 1 years accounted for $53.81 \%$. It shows that most members in this survey is a long-term member of Huawei brand community.

\section{Reliability and Validity Analysis}

Table 1 Exploratory factor analysis data

\begin{tabular}{|c|c|c|c|c|c|c|c|}
\hline variable & No. & $\begin{array}{c}\text { Factor } \\
\text { load }\end{array}$ & $\begin{array}{c}\text { Cumulative } \\
\text { explanation } \\
\text { variance }\end{array}$ & variable & No. & $\begin{array}{c}\text { Factor } \\
\text { load }\end{array}$ & $\begin{array}{l}\text { Cumulative } \\
\text { explanation } \\
\text { variance }\end{array}$ \\
\hline \multirow{3}{*}{ IFE } & Q1 & 0.810 & \multirow{3}{*}{$60.864 \%$} & \multirow{6}{*}{ CC } & Q18 & 0.812 & \multirow{6}{*}{$64.806 \%$} \\
\hline & Q2 & 0.854 & & & Q19 & 0.839 & \\
\hline & Q3 & 0.748 & & & Q20 & 0.868 & \\
\hline \multirow{3}{*}{$\mathrm{EE}$} & Q4 & 0.803 & \multirow{3}{*}{ 77.756\% } & & Q21 & 0.792 & \\
\hline & Q5 & 0.920 & & & Q22 & 0.724 & \\
\hline & Q6 & 0.917 & & & Q23 & 0.788 & \\
\hline \multirow{4}{*}{ ITE } & Q7 & 0.842 & \multirow{4}{*}{$68.767 \%$} & \multirow{4}{*}{ BL } & Q24 & 0.957 & \multirow{4}{*}{$89.329 \%$} \\
\hline & Q8 & 0.778 & & & Q25 & 0.958 & \\
\hline & Q9 & 0.845 & & & Q26 & 0.950 & \\
\hline & Q10 & 0.850 & & & Q27 & 0.915 & \\
\hline \multirow{3}{*}{$\mathrm{TE}$} & Q11 & 0.880 & \multirow{3}{*}{$77.880 \%$} & \multirow{7}{*}{$\mathrm{CP}$} & Q28 & 0.711 & \multirow{7}{*}{ 70.199\% } \\
\hline & Q12 & 0.918 & & & Q29 & 0.826 & \\
\hline & Q13 & 0.848 & & & Q30 & 0.908 & \\
\hline \multirow{4}{*}{ SE } & Q14 & 0.766 & \multirow{4}{*}{$66.445 \%$} & & Q31 & 0.845 & \\
\hline & Q15 & 0.786 & & & \multirow{3}{*}{ Q32 } & \multirow{3}{*}{0.886} & \\
\hline & Q16 & 0.822 & & & & & \\
\hline & Q17 & 0.882 & & & & & \\
\hline \multicolumn{8}{|c|}{$\begin{array}{l}\text {-The variables KMO statistics are more than } 0.7 \text {; } \\
\text {-All variables of the Bartlett spherical test statistic of Sig are .000 }(<0.05) \text {. } \\
\text {-IFE [Information Experience], EE [Entertainment Experience], ITE [Interactive Experience], TE } \\
\text { [Thinking Experience], SE [Service Experience], CC [Community Commitment], BL [Brand Loyalty], CP } \\
\text { [Community Participation] }\end{array}$} \\
\hline
\end{tabular}


We used the Cronbach alpha coefficient to measure the reliability, using exploratory factor analysis to analyze the validity. Usually, if the Cronbach alpha coefficient achieve 0.7 , it can be acceptable. The results show that the $\alpha$-coefficients of information experience, entertainment experience, interactive experience, thinking experience, service experience, community commitment, brand loyalty and community participation are $0.776,0.856,0.847,0.857,0.828,0.886,0.958,0.892$ respectively. These data indicate that the questionnaire has a good reliability. Before conducting exploratory factor analysis, we need conduct KMO test and Bartlett spherical test to determine whether the questionnaire data is suitable for factor analysis. As seen in Table 1, that several observed variables used to measure the same potential variable can be reduced to a common factor, and the common factor can explain the variance of more than $60 \%$. The explanation degree can be acceptable. The factor load of each observation variable is more than 0.5 , and each variable has good convergence validity, and all the observed variables can be retained.

\section{Structural Equation model Analysis}

In this section, we carried out the hypothesis testing in three steps. First, we examined the direct impact of community experience on brand loyalty, then taking community commitment into the model to verify its intermediary effect. Finally, we discussed the moderating effect of community participation. Before using the structural equation to carry out the hypothesis test, we must confirm the model-fitting degree. The higher the model-fitting degree, the higher the feasibility of the model is, and the more valuable the parameter estimation is.

(1) Hypothetical testing of the influence of online brand community experience

The structural equation model-fitting index of the experience direct influence (model 1) is $\mathrm{X}^{2} / \mathrm{df}=2.424$, RMSEA $=0.085$, GFI $=0.810$, CFI $=0.908$, NFI $=0.855$. The model-fitting degree is generally acceptable. As seen in Table 2, hypothesis $\mathrm{H} 1$ is verified. That is, online brand community experience has a significant impact on brand loyalty $(\mathrm{p}<0.001)$, and the path coefficient is 0.914 .

Table 2 Hypothetical testing table of the influence of online brand community experience

\begin{tabular}{|c|c|c|c|c|}
\hline Hypothesis & $\begin{array}{c}\text { Non-standardized } \\
\text { load factor }\end{array}$ & Standard error & T (C.R.) & Hypothetical testing \\
\hline H1 & $0.914^{* * *}$ & 0.114 & 8.056 & True \\
\hline$-\quad * * *$ indicates $\mathrm{p}<0.001$
\end{tabular}

Then we established another structural equation model of the direct influence of each experience dimension on brand loyalty (model2): $\mathrm{X}^{2} / \mathrm{df}=4.505$, RMSEA $=0.134, \mathrm{GFI}=0.674, \mathrm{CFI}=0.774$, $\mathrm{NFI}=0.729$ ). Since $\mathrm{X}^{2} / \mathrm{df}$ is greater than 4 and RMSEA is greater than 0.1 , which means the model-fitting is poor, we need to modify the model. According to modification index MI, we set up the error correlation between some variables. The revised model indicators are as follows: $\mathrm{X}^{2} / \mathrm{df}=2.927, \mathrm{RMSEA}=0.086, \mathrm{GFI}=0.800, \mathrm{CFI}=0.880$, NFI $=0.831$. These data meets the basic requirements. Based on the revised model, the data on the impact of each experience dimension on brand loyalty is shown in Table 3. The results show that hypotheses H1(a), H1(d) and H1(e) are verified, and hypotheses H1(b)and H1(c) has not been verified.

Table 3 Hypothetical testing table of the influence of each experience dimensions

\begin{tabular}{|c|c|c|c|c|}
\hline Hypothesis & Non-standardized load factor & Standard error & T (C.R.) & Hypothetical testing \\
\hline H1(a) & $0.473^{*}$ & 0.189 & 2.505 & True \\
\hline H1(b) & 0.072 & 0.111 & 0.646 & False \\
\hline H1(c) & -0.163 & 0.142 & -1.138 & False \\
\hline H1(d) & $0.586^{* * *}$ & 0.101 & 5.786 & True \\
\hline H1(e) & $0.380^{* *}$ & 0.137 & 2.770 & True \\
\hline- - *** indicates $\mathrm{p}<0.001, * *$ indicates $\mathrm{p}<0.01, *$ indicates $0.01<\mathrm{p}<0.05$ \\
\hline
\end{tabular}


(2) Hypothetical testing of mediation effect of community commitment

Next, we established the structural equation model of the mediation effect of community commitment (model 3) $\left(\mathrm{X}^{2} / \mathrm{df}=2.470\right.$, RMSEA=0.087, GFI=0.716, CFI=0.878, NFI=0.813). The model-fitting is generally acceptable, but there is still room for improvement. According to modification index MI, we established the error correlation between the observed variables Q9 and Q10. After the correction, it was found that the indexes related to the model-fitting were improved $\left(\mathrm{X}^{2} / \mathrm{df}=2.275\right.$, RMSEA $=0.081$, GFI $=0.810$, CFI $\left.=0.900, \mathrm{NFI}=0.836\right)$.

Based on the revised model, we have obtained the data in Table 4. The p-value of each path is less than 0.05 , which means (a) hypothesis $\mathrm{H} 1$ is verified again, that is, the online brand community experience positively affect brand loyalty with a path coefficient of 0.422 ; (b) hypothesis $\mathrm{H} 2$ is verified, that is, the online brand community experience have positive impact on brand commitment with a path coefficient of 0.814 ; (c) hypothesis $\mathrm{H} 3$ is verified, that is, the community commitment has a positive impact on brand loyalty with a path coefficient of 0.553 . After the variable community commitment joined into the model, the path coefficient between community experience and brand loyalty declined from the original 0.914 to 0.422 . Community commitment plays a partial intermediary role between online brand community experience and brand loyalty.

Table 4 Hypothetical testing table of community commitment mediation effect

\begin{tabular}{|c|c|c|c|c|}
\hline Hypothesis & Non-standardized load factor & Standard error & T (C.R.) & Hypothetical testing \\
\hline H1 & $0.422^{*}$ & 0.191 & 2.212 & True \\
\hline H2 & $0.814^{* * *}$ & 0.078 & 10.430 & True \\
\hline H3 & $0.553^{* *}$ & 0.193 & 2.867 & True \\
\hline$-\quad * * *$ indicates $\mathrm{p}<0.001,{ }^{* *}$ indicates $\mathrm{p}<0.01, *$ indicates $0.01<\mathrm{p}<0.05$ \\
\hline
\end{tabular}

(3)Hypothetical testing of moderating effect of the degree of community participation

There are five observation variables for the community participation. The samples are divided into two categories by rapid clustering: high participation (100) and low participation (97). Based on the model 3, we testes the moderating effect by structural equation multi-group analysis. The results shows that in the case where the default model is assumed to be true, the p-value of the modulating effect model is greater than 0.05, indicatig that the whole moderating effect is not significant. It is only a description of the overall phenomenon, so we need to examine the individual variable by "parameter matching". From the table "Critical Ratios for Differences between Parameters", we found that the critical ratios between each pair variables are less than 1.96. It further illustrates that the regulatory effect of the community participation is not significant, that is, hypotheses H4, H5 and H6 have not been verified.

\section{Summary}

The hypotheses are tested with the structural equation modeling method. It is found that the online brand community experience have a positive impact on brand loyalty, and the information experience, thinking experience and service experience have a significant impact on brand loyalty., while the entertainment experience and interactive experience have no significant impact on brand loyalty. Community commitment plays a partial intermediary role between online brand community experience and brand loyalty. Generally, if community members' participation is different, their community commitment and brand loyalty may be different. However, this study found that the moderating effect of community participation is not significant. The possible reason is that the community experience is the subjective feeling of community members about the process of participation, and may be more influenced by the individual's personality.

In fact, there are some limitations in this study. First of all, the proportion of men and women in this sample is not balanced. Secondly, we only considered the single intermediary effect of 
community commitment. In the further research, we can discuss deeply multiple intermediary effect between community experience and brand loyalty.

Online brand community, as a link between brands and consumers, is an important battlefield of building brand and enhancing the brand value. Enterprises should take into account the various aspects of community members experiences, particularly improving their information experience, service experience and thinking experience. First, the community can provide high-quality content, including the professional content made by community operators, the excellent content published by the members, as well as the interesting comments and analysis. Second, enterprises should bring together the individual's interests and needs to provide accurate, high quality and people-oriented service. Finally, in the daily activities, enterprises should stimulate members to think and deepen the bond with the brand. Enterprises can also gather the members who have interesting new ideas to contribute their wisdom to accelerate product innovation.

\section{References}

[1] Muniz A.M., and O’Guinn, T.C. Brand community. Journal of Consumer Research. 27(2001) 412-432.

[2] Schouten J W, Mcalexander J H, Koeing H F, Transcendent customer experience and brand community [J]. Journal of the Academy of Marketing Science. 35(2007)357-368.

[3] Xue Haibo, Wang Xinxin. Research of Mechanism of Impact of Brand Community on Brand Loyalty —Based on the Transcendent Consumer Experience Perspective. China Industrial Economics, 10(2009)96-107.

[4] Holbrook M.B. The Millennial Consumer in the Texts of Our Times: Experience and Entertainment. Journal of Macromarketing. 2(2000)178-192.

[5] Csikszentmihalyi M.Beyond Boredom and Anxiety: Experiencing Flow in Work and Play. San Francisco, CA: Jossey-Bass, 1975.

[6] Ren Feng. Brand Community Consumption Experience and Brand Commmunity Intergration: A Study Based on the Mediating Effect of Flow Experience. JOURNAL OF ZHONGNAN UNIVERSITY OF ECONOMICS AND LAW. 4(2014)151-156.

[7] Cova B, Pace S, Park D.J. Global brand communities across borders: the war hammer case. International Marketing Review. 24(2007)313-329.

[8] Nambisan, P., Watt, J. H.. Managing customer experiences in online product communities. Journal of Business Research. 64(2011)889-895.

[9] Sha Zhenquan, Jiang Yuwei, Wen Fei. An Empirical Study: Effects of the Experiences of the Virtual Brand Community on the Brand Identification of the Community Members. Management Review. 22(2010)79-88.

[10] Xue Haibo. Theory and Model Construction of Brand Community Functionary Mechanism. Foreign Economics \& Management. 34(2012)50-57.

[11] Fan Zhiguo, Guo Jingli. Empirical Research on Virtual Brand Community Experience Effect on Customer Purchase Intention-Based on the Mediating Effect of Perceived Uncertainty Reduction[J]. Journal of Industrial Technological Economics, 11(2014)29-37.

[12] De Vries, L., Gensler, S., Leeflang, P. S.. Popularity of brand posts on brand fan pages: an investigation of the effects of social media marketing. Journal of Interactive Marketing. 26(2012)83-91.

[13] Meyer J P, Allen N J. A three-component conceptualization of organizational commitment. Human Resource Management Review. 1(1991)61-89. 
[14] He Aizhong, Li Xue. A Study on the Evolutionary Mechanism of Motivations in the Formation of Online Brand Community Members' Sustained Participation Behavior. Management Review. 12(2015)733-743.

[15] Zhou Zhimin, Zhen Yaqin. From Brand Community Identification to Brand Loyalty: A Study on Mediating and Moderating Effects. Journal of Shenzhen University (Humanities \& Social Sciences). 28(2011)84-90.

[16] Fan Xiaoping, Ma Qingguo. A Study on the Impact of Interactivity on Online Purchasing Intent Based on Virtual Community. Journal of Zhejiang University (Humanities and Social Sciences).39(2009)94-102.

[17] Schmitt B. Experiential marketing. Journal of marketing management. 15(1999)53-67.

[18] Allen, Natalie J. and John P. Meyer. The measurement and antecedents of affective, continuance and normative commitment to the organization. Journal of Occupational Psychology. 63(1990)1-18.

[19] Bao Lin. Research on Measurement Index System of Online Brand Loyalty. Jiangsu Commercial Forum. 7(2010) 122-123.

[20] Madupu. Online brand community participation: antecedents and consequences. Advances in Consumer Research.35(2008)853-854. 